\title{
Mansikantuotannon kilpailuetu Suomessa ja Virossa
}

\author{
Anu Koivisto \\ MTT Taloustutkimus \\ Luutnantintie 13 \\ 00410 Helsinki \\ anu.koivisto@mtt.fi
}

\section{Tiivistelmä}

Euroopan unionin kevään 2004 laajentumisen myötä Suomi ja Viro kuuluvat samaan sisämarkkinaalueeseen, minkä pelätään lisäävän kilpailua mansikantuotannossa. Tämän tutkimuksen tavoitteena oli tarkastella Suomen ja Viron mansikantuotannon kilpailukykyä sekä siihen vaikuttavia tekijöitä Porterin kilpailuteorioihin perustuen.

Mansikka on sekä Suomessa että Virossa yksi tärkeimmistä marjakasveista. Vuonna 2003 Suomessa mansikkaa viljeltiin noin 3800 hehtaarilla ja Virossa 1200 hehtaarilla. Suomen ja Viron mansikantuotannon tekniikat ovat melko samanlaiset. Suurimpana erona Virossa on varhaisemmin alkava ja pidempään jatkuva kasvukausi.

Tutkimuksessa kilpailuetua tarkasteltiin hierarkkisesti siten, että yritystason kilpailuedusta tarkastelu laajennettiin toimialatason kilpailuedun tarkasteluun ja edelleen maatason tarkasteluun. Tutkimusmenetelmänä käytettiin tapaustutkimusta. Tutkimuksessa aineistona käytettiin tilastoaineistoja, MTT Taloustutkimuksen kannattavuuskirjanpitotilojen aineistoja sekä Virossa mansikkatiloille tehtyä kyselyaineistoa.

Tutkimuksen mukaan Suomen suurilla mansikkatiloilla mansikantuotannon kulut olivat noin $2,0 € / \mathrm{kg}$, keskisuurilla $2,7 € / \mathrm{kg}$ ja pienillä $2,8 € / \mathrm{kg}$. Virossa mansikantuotannon kulut olivat suurilla mansikkatiloilla $0,62 € / \mathrm{kg}$, keskisuurilla $0,82 € / \mathrm{kg}$ ja pienillä $1,24 € / \mathrm{kg}$. Mansikantuotannon kulut sisälsivät ainoastaan suoraan mansikantuotantoon ja ainoastaan todellista rahan liikettä aiheuttavat kulut.

Tutkimuksen tulosten mukaan Virolla oli yritystasolla kustannusetu mansikan tuottamisessa suurilla ja keskisuurilla mansikkatiloilla. Kustannusetu muodostui pääasiassa Viron alhaisemmista palkkakustannuksista. Tämä kustannusetu ei kuitenkaan ole pysyvä, sillä esimerkiksi vuodesta 1998 vuoteen 2003 Viron palkkataso on noussut 67 prosenttia ja tulee ilmeisesti edelleenkin nousemaan.

Toimialatasolla mansikantuotannon kilpailuetua tarkasteltiin viiden eri osatekijän avulla, mitkä olivat 1) alan kilpailijat, 2) alan mahdolliset tulokkaat, 3) ostajat, 4) korvaavat tuotteet ja 5) toimittajat. Toimialatasolla Suomen vahvuus oli markkinarakenne, sillä suuri osa Suomessa tuotetuista mansikoista myydään suoraan tilalta joko valmiiksi poimittuna tai itsepoimintana suoraan kuluttajille. Virossa merkittäviä määriä mansikkaa myydään suoraan teollisuudelle, mutta teollisuuden ostot tulevat tulevaisuudessa todennäköisesti vähenemään. Toimialatasolla Viron vahvuus oli mansikoiden kysynnän lisääntyminen, mikä aiheutuu elintason noususta ja kotitarveviljelyn vähenemisestä.

Maatasolla kilpailuedun tarkastelu perustui neljään eri osatekijään, mitkä olivat 1) tuotannontekijä olot, 2) yrityksen strategia, rakenne ja kilpailuympäristö, 3) kysyntäolot ja 4) lähi- ja tukialat. Suomen vahvuuksia maatasolla olivat runsas mansikan tutkimustoiminta ja kehittynyt infrastruktuuri. Tarkasteltaessa markkinainformaatioon perustuvan laskentamallin perusteella kilpailuetua, todettiin Virolla olevan Suomeen verrattuna kilpailuetu mansikantuotannossa.

Asiasanat: kilpailukyky, mansikan viljely, kilpailuteoria, tuotantokustannus, tuotto 


\section{Johdanto}

Euroopan unionin laajentumisen myötä Suomi ja Viro kuuluvat samaan sisämarkkina-alueeseen. Samoilla sisämarkkinoilla toimimiselle on ominaista tuotteiden vapaa liikkuvuus. Tämän pelätään lisäävän kilpailua etenkin sellaisten tuotteiden osalta, joiden hinta on Virossa merkittävästi Suomea alhaisempi. Yksi tällainen tuote on mansikka.

Mansikka on sekä Suomessa että Virossa yksi tärkeimmistä marjakasveista. Vuonna 2003 Suomessa viljeltiin mansikkaa noin 3800 hehtaarilla ja Virossa 1200 hehtaarilla (MMM 2004, Statistical office of Estonia 2004). Mansikan keskimääräinen satotaso oli Suomessa $2131 \mathrm{~kg} / \mathrm{ha}$ vuonna 2003, kun satotaso Virossa oli $1333 \mathrm{~kg} / \mathrm{ha}$ Food and Agriculture Organization of the United Nations eli FAO:n (2004) tilastojen mukaan. Libekin (2002) ja Värnikin (2004) mukaan Viron keskimääräinen satotaso on kuitenkin huomattavasti FAOn arvoja korkeampi, $4000-5000 \mathrm{~kg} / \mathrm{ha}$.

Tämän tutkimuksen tavoitteena oli arvioida mansikantuotannon kilpailuetua Suomessa ja Virossa sekä määrittää kilpailuetuun vaikuttavia tekijöitä. Tutkimuksessa käytetään ainoastaan termiä kilpailuetu, mikä kattaa myös termit kilpailukyky ja kilpailuhaitta.

Tutkimuksen kilpailuetutarkastelu pohjautuu Porterin $(1987,1985,1990)$ kilpailuetua koskeviin teorioihin. Kilpailuetua tarkastellaan hierarkkisesti siten, että pienimpänä tarkasteluyksikkönä on tilatason tarkastelu. Toisena tarkastelutasona on toimialan tarkastelu ja kolmantena maatason tarkastelu. Tutkimuksessa käytetään tapaustutkimusmenetelmää.

Puutarhatalouden piirissä on Suomessa tehty aiemminkin maiden välisiä vertailuja. Suomalaisen puutarhatuotannon asemaa Euroopan unionissa ovat tilastoluonteisesti tarkastelleet muun muassa Laitinen (1995) ja Lehtimäki (1998). Lähemmin tämän tutkimuksen näkökulmaa sivuava tutkimus on Mäkelän ym. (1995) tutkimus, jossa tarkasteltiin vihannesten alkutuotannon ja jalostuksen menestystekijöitä. Tutkimuksessa verrattiin suomalaista vihannestuotanto- ja vihannestenjalostussektoreita Ruotsin, Tanskan, Hollannin, Belgian, Englannin ja Puolan vastaaviin sektoreihin.

Suomen ulkopuolelta löytyy puutarhatuotannon kilpailuetua käsitteleviä tutkimuksia, jotka pohjautuvat Porterin kilpailuteorioihin. Tutkimuksissa on määritelty joko yksittäisen kasvin tai sektorin kilpailuetu. Näistä tutkimuksista esimerkkeinä Unkarissa Hajdun ja Lanknerin (1998) tekemä tutkimus Unkarin elintarviketeollisuuden kilpailuedusta, Traillin ja Pittsin (1997) tekemä tutkimus IsoBritannian omenan-, mansikan-, ja sienituotannon kilpailuedusta, sekä Kleijnin (1996) tekemä tutkimus Hollannin seitsemän eri puutarhasektorin kilpailuedusta.

\section{Aineisto ja menetelmät}

Tutkimuksessa käytettiin sekä kvalitatiivisia että kvantitatiivisia aineistoja. Kvalitatiivisia aineistoja olivat Virosta kyselytutkimuksena kerätyt tilatason aineistot. Suomen tilatason aineistot koostuivat MTT Taloustutkimuksen kannattavuuskirjanpitotilojen aineistoista. Tutkimuksessa oli mukana 26 tilaa Suomesta ja 13 tilaa Virosta. Tutkimuksessa käytettiin termiä mansikkatila huolimatta siitä, täyttivätkö tilat tilatypologian mukaiset mansikkatilan vaatimukset.

Tutkimuksen mansikkatilat jaettiin kolmeen tilakokoluokkaan niiden mansikanviljelypinta-alan perusteella: suuret mansikkatilat, keskisuuret mansikkatilat ja pienet mansikkatilat. Tilojen ryhmittely mahdollisti maavertailun lisäksi myös eri tilakokoluokkien kilpailuedun vertailun. Tilakokoluokkien jakoperusteet noudattivat maakohtaisia mansikkatilojen kokojakaumia, joiden mukaan Viron mansikkatilat painottuvat Suomea enemmän alle 1,0 ha tiloihin. Suomessa suurilla mansikkatiloilla mansikan viljelyala oli 5,0 ha tai enemmän, keskisuurilla $1,0-4,9$ ha ja pienillä $0,5-0,9$ ha. Virossa suurten mansikkatilojen viljelypinta-ala oli 3,0 ha tai enemmän, keskisuurilla 1,0-2,9 ha ja pienillä alle 0,9 ha.

Tilatason taloudelliset aineistot käsittivät mansikantuotantoon suoraan liittyvät kassaperusteiset tuotot ja kulut. Laskennalliset erät, kuten poistot, korot ja oman työn palkkavaatimus, jätettiin tarkastelun ulkopuolelle. Taulukossa 1 on lueteltu tutkimuksessa mukana olevat tuotto- ja kustannuserät. 
Taulukko 1. Tuotto- ja kustannuserät Suomen ja Viron tutkimustiloilla.

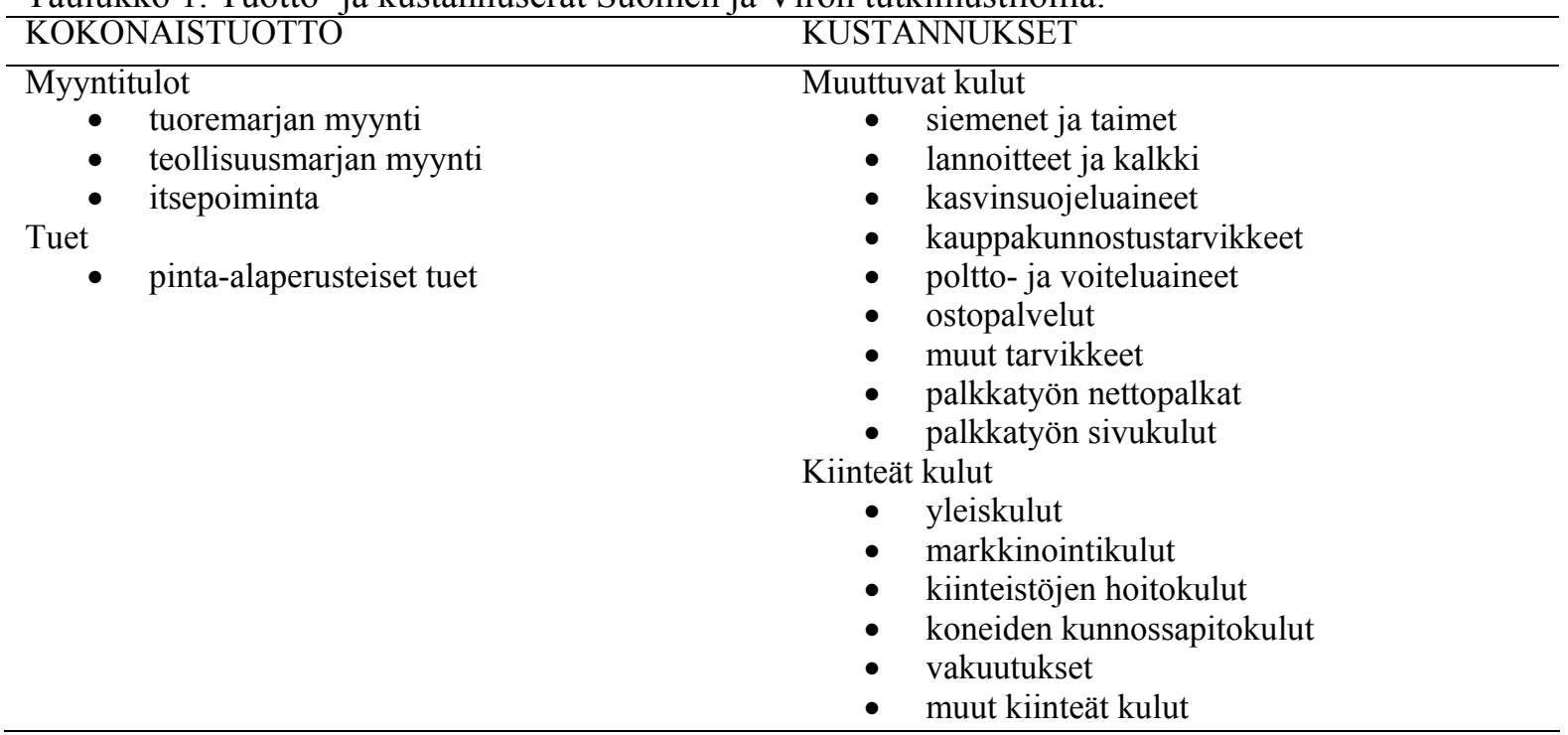

Toimiala- ja maatason tarkastelussa aineistona käytettiin pääasiassa tilastoaineistoja. Kilpailuetua tarkasteltiin myös aiempien tutkimusten tulosten avulla toimiala- ja maatasolla. Tutkimusmenetelmänä käytettiin tapaustutkimusta.

Tutkimuksessa kilpailuetua tarkasteltiin tilatasolla yksinomaan kustannusedun näkökulmasta. Erilaistamisen luoma kilpailuetu jätettiin tarkastelun ulkopuolelle. Tilatason kustannusetutarkastelu tehtiin Porterin (1985) teorian mukaisella arvoketjutarkastelulla, jossa mansikantuotanto jaettiin toimintoihin. Tutkimuksessa tarkastellut mansikantuotannon toiminnot olivat viljelmän perustaminen, lannoitus, kasvinsuojelu, sadonkorjuu ja pakkaus sekä markkinointi. Tarkastelussa mansikantuotannon kulut kohdistettiin arvoketjun toiminnoille, jolloin pystyttiin havainnoimaan kustannusedun lähteet.

Toimialatasolla kilpailuetua tarkasteltiin Porterin (1987) teoriaan mukaan viiden osatekijän perusteella. Tarkasteltavat kilpailuetuun vaikuttavat tekijät olivat: 1) alan kilpailijat, 2) alan mahdolliset tulokkaat, 3) ostajat, 4) korvaavat tuotteet ja 5) tavaran toimittajat. Maatasolla mansikantuotannon kilpailuetua tarkasteltiin (Porter 1990) kuutta eri osatekijää tarkastellen. Nämä kilpailuetuun vaikuttavat osatekijät olivat: 1) tuotannontekijäolot, 2) yrityksen strategia, rakenne ja kilpailuympäristö, 3) kysyntäolot, 4) lähi- ja tukialat, 5) toimintaympäristön muutokset ja 6) valtiovalta. Toimiala- ja maatason tarkastelussa kilpailuedun mittaamiseen käytettiin myös markkinainformaatioon perustuvaa laskentamallia, jota ovat käyttäneet esimerkiksi Frohberg ja Hartmann (1998) tarkastellessaan Baltian maiden eri maataloussektoreiden kilpailuetua. Tutkimuksessa käytettiin nelikenttä, eli SWOT- analyysiä, kiteyttämään tila-, toimiala- ja maatasolla kilpailuetuun vaikuttavat tekijät.

\section{Tulokset ja tulosten tarkastelu}

Mansikantuotannon kulut olivat alhaisimmat Viron suurilla ja keskisuurilla tiloilla, joilla kulut olivat keskimäärin noin $4000 € /$ ha suurilla ja $4300 € /$ ha keskisuurilla tiloilla. Suomen suurilla mansikkatiloilla mansikantuotannon kulut olivat kolmanneksi alhaisimmat, noin $6700 € /$ ha. Suomessa eri tilakokoluokkien välillä ei ollut suuria eroja hehtaarin kuluissa. Suomen mansikkatilojen kulut vaihtelivat $6700-7600 € /$ ha välillä. Viron pienillä mansikkatiloilla kulut olivat suurimmat, $8500 € /$ ha. Tähän on osittain syynä pienen viljelyalan hyvin intensiivinen viljely (kuva 1).

Tutkimuksen mukaan Suomen suurilla mansikkatiloilla mansikantuotannon kulut olivat noin 2,0 $€ / \mathrm{kg}$, keskisuurilla $2,7 € / \mathrm{kg}$ ja pienillä $2,8 € / \mathrm{kg}$. Virossa mansikantuotannon kulut olivat suurilla mansikkatiloilla $0,62 € / \mathrm{kg}$, keskisuurilla $0,82 € / \mathrm{kg}$ ja pienillä $1,24 € / \mathrm{kg}$

Arvoketjutarkastelun perusteella havaittiin, että Viron kustannusetu suurilla ja keskisuurilla tiloilla johtui sadonkorjuusta ja pakkaamisesta, sillä niihin liittyvät kulut hehtaaria kohden olivat Suomen vastaavia tilakokoluokkia huomattavasti alhaisemmat. Viron mansikkatiloille muodostui jonkin verran kustannusetua myös lannoituksesta ja kasvinsuojelusta. Suomessa sen sijaan markkinoinnin kulut olivat Viroa alhaisemmat. Tähän osaltaan vaikuttaa se, että Suomessa markkinointikuluihin luo- 
kitellut mansikanvälittäjien välityspalkkiot on sisällytetty viljelijöille maksettavaan mansikanhintaan. Virossa sen sijaan välityspalkkiot ilmenevät erillisinä kuluina.

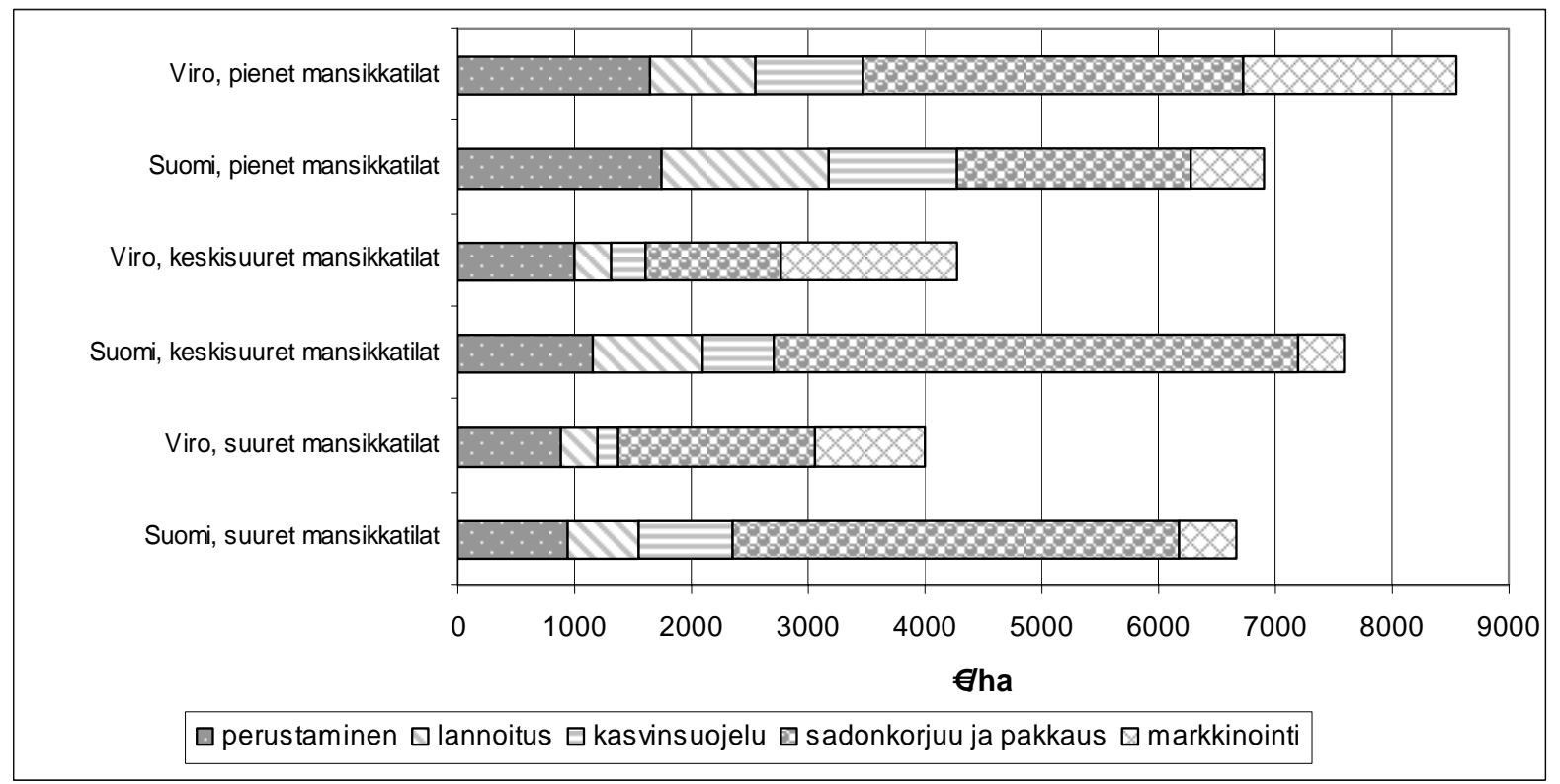

Kuva 1. Mansikantuotannon kustannusetu Suomessa ja Virossa.

Mansikantuotannon kilpailuetuun vaikuttavat myös maan yleinen hintataso ja etenkin mansikantuotannon tulot. Tutkimuksessa makohtaisia kustannustasoeroja pyrittiin vähentämään suhteuttamalla mansikantuotannon kulut tuottoihin. Suomen suurten mansikkatilojen kilpailuetu oli tämän tarkastelutavan perusteella paras, sillä niillä kulujen osuus tuotoista oli pienin, noin 39 prosenttia. Ero Viron suuriin mansikkatiloihin ei kuitenkaan ollut merkittävä, sillä Viron suurilla mansikkatiloilla kulujen osuus tuotoista oli 46 prosenttia. Suomen pienten ja keskisuurten mansikkatilojen kilpailuetu oli heikko, sillä niillä mansikantuotannon kulut olivat tuottoja suuremmat.

Toimialatasolla Suomen vahvuus oli mansikan markkinarakenne, sillä suuri osa Suomessa tuotetuista mansikoista myydään suoraan tilalta joko valmiiksi poimittuna tai itsepoimintana suoraan kuluttajille. Virossa merkittäviä määriä mansikkaa myydään suoraan teollisuudelle. Toimialatasolla Viron vahvuus oli mansikoiden kysynnän lisääntyminen, mikä aiheutuu elintason noususta ja kotitarveviljelyn vähenemisestä. Mansikantuotannon heikkoudet perustuvat kummassakin maassa mansikantuotannon toimialalle tyypillisiin piirteisiin, kuten käsityövaltaisuuteen ja perustuotteen tuottamiseen hajaantuneella alalla.

Suomen vahvuuksia maatasolla olivat kehitystuotannontekijät, kuten korkeatasoinen mansikantutkimustoiminta ja kehittynyt infrastruktuuri. Viron vahvuus mansikantuotannossa oli kustannusetu, mikä johtui osaksi Viron Suomea paremmista perustuotannontekijöistä kuten suotuisammasta ilmastosta ja maan paremmasta luontaisesta viljavuudesta.

Maakohtaiset heikkoudet perustuivat pääasiassa kunkin valtion asettamiin toimialaa koskeviin säädöksiin ja taloudellisiin puitteisiin. Uhat perustuvat kummassakin maassa sekä maan sisäisiin että ulkoisiin uhkiin. Uhkina koetut asiat ovat kummassakin maassa melko samankaltaisia, kuten tuontimansikan uhka sekä poimijoiden saannin vaikeus.

Markkinainformaatioon perustuvan laskentamallin avulla havaittiin Virolla olevan kilpailuetu Suomeen verrattuna. Kuvassa 2 on SWOT-analyysin muodossa kilpailuetuun vaikuttavat tila-, toimiala- ja maatason tekijät. 


\begin{tabular}{|c|c|}
\hline \multicolumn{2}{|l|}{ VAHVUUDET } \\
\hline Suomi & Viro \\
\hline $\begin{array}{ll}\text { - } & \text { mansikoiden myynti suoraan tilalta ja itse- } \\
\text { poiminnan suosio } \\
\text { - } \\
\text { - } \\
\text { - } \\
\text { - } \\
\text { - } \text { matimaisen mansikanviljelijöiden korkea järjestäytymisas- } \\
\text { te } \\
\text { hyvät pääomaresurssit ja investointiavus- } \\
\text { tukset }\end{array}$ & $\begin{array}{ll}\text { - } & \text { yritystason kustannusetu } \\
\text { - } & \text { vähäinen keväthallojen määrä, ei lisätyötä } \\
\text { hallasadetuksesta } \\
\text { - } \quad \text { Suomea paremmat perustuotannontekijät }\end{array}$ \\
\hline \multicolumn{2}{|l|}{ MAHDOLLISUUDET } \\
\hline Suomi & Viro \\
\hline $\begin{array}{ll}\text { - } & \text { tuotteen erilaistaminen } \\
\text { - } & \text { marjojen kulutuksen lisääntyminen } \\
\text { - } & \text { ulkomaisten poimijoiden käyttö } \\
\text { - } & \text { viljelijöiden positiivinen asenne, tuotannon } \\
\text { laajentaminen ja uuden teknologian käyt- } \\
\text { töönotto } \\
\text { - } \quad \text { hyvin toimivat välittäjät } \\
\text { - } \quad \text { tuote- ja tuotantotekniikkainnovaatiot }\end{array}$ & $\begin{array}{ll}\text { - } & \text { tuotteen erilaistaminen } \\
\text { - } & \text { tilamyynnin ja itsepoiminnan lisääminen } \\
\text { - } & \text { kotitarveviljelyn vähentyminen } \\
\text { - } & \text { marjojen kulutuksen lisääntyminen } \\
\text { - } & \text { ulkomaisten poimijoiden käyttö } \\
\text { - } & \text { EU:n investointituet } \\
\text { - } & \text { hyvin toimivat välittäjät } \\
\text { - } & \text { tehokkaat viljelymenetelmät vienti Suo- } \\
& \text { meen, Ruotsiin ja Venäjälle }\end{array}$ \\
\hline \multicolumn{2}{|l|}{ HEIKKOUDET } \\
\hline Suomi & Viro \\
\hline $\begin{array}{ll}\text { - } & \text { alan heikko houkuttelevuus } \\
\text { - } & \text { perustuote, vain vähän erilaistamista } \\
\text { - } & \text { tuottajilla heikko asema toimittajiin nähden } \\
\text { - } & \text { minipalkkalaki ja korkeat palkkakustannuk- } \\
\text { - } & \text { ket } \\
\text { lista kövaltainen ala, ei toistaiseksi mahdol- } \\
\text { listaa }\end{array}$ & $\begin{array}{ll}\text { - } & \text { alan heikko houkuttelevuus } \\
\text { - } & \text { perustuote, vain vähän erilaistamista } \\
\text { - } & \text { tuottajilla heikko asema toimittajiin nähden } \\
\text { - } & \text { vähän pääomaa investointeihin } \\
\text { - } & \text { huonokuntoinen infrastruktuuri }\end{array}$ \\
\hline \multicolumn{2}{|l|}{ UHAT } \\
\hline Suomi & Viro \\
\hline $\begin{array}{ll}\text { - } & \text { mansikoiden rahamääräisen kulutuksen } \\
\text { pieneneminen } \\
\text { - } \text { mansikan tuonti } \\
\text { muiden marjakasvien kulutuksen lisäänty- } \\
\text { - } \text { minen } \\
\text { - } \text { maimijoiden saannin vaikeus } \\
\text { - } \text { suomalaisten tuoteinnovaatioiden leviämi- } \\
\text { - } \text { nen } \\
\text { - } \text { kU-rajoitukset } \\
\text { kasvitaudit }\end{array}$ & $\begin{array}{l}\text { - } \quad \text { teollisuusostajien käyttäytyminen } \\
\text { - } \text { mansikan tuonti } \\
\text { - } \text { minen marjakasvien kulutuksen lisäänty- } \\
\text { - } \quad \text { poimijoiden saannin vaikeus } \\
\text { - markkinahäiriöt } \\
\text { - EU:n mukanaan tuomat rajoitukset ja laatu- } \\
\text { - } \quad \text { kaatimusten tiukentuminen } \\
\text { kasvitaudit }\end{array}$ \\
\hline
\end{tabular}

Kuva 2. SWOT-analyysi Suomen ja Viron kilpailuedusta.

\section{Johtopäätökset}

Yritystasolla suurin kilpailuetu oli Viron suurilla ja keskisuurilla mansikkatiloilla. Merkittävin Viron kilpailuedun lähde oli sadonkorjuun ja pakkauksen toiminto, ja siinä etenkin Viron Suomea alhaisemmat palkkakulut. Kun poimintakulut Suomessa olivat noin $1,00 € / \mathrm{kg}$, olivat ne virossa noin $0,20 € / \mathrm{kg}$. Vaikka kilogrammakohtaiset poimintakulut olivat Virossa huomattavasti Suomea alhaisemmat, ei ero hehtaarikohtaisissa poimintakuluissa ollut yhtä suuri. Syynä tähän oli Viron huomattavasti Suomea suuremmat hehtaarikohtaiset satotasot ja siten myös huomattavasti suurempi poimintatyön määrä.

Kilpailuetua muodostui Viron mansikkatiloille myös lannoituksen ja kasvinsuojelun toiminnoista. Kasvinsuojelun toiminnon kilpailuetu perustui pääasiassa vähäisempiin tautiaineiden käyttömääriin. Todennäköisesti kasvinsuojeluaineiden käyttö tulee Virossa kuitenkin tulevaisuudessa lisääntymään tiukentuneitten laatuvaatimusten myötä, jolloin kasvinsuojelun toiminnon kilpailuetu vähentyy. 
Kun kilpailuetua tarkasteltiin suhteuttamalla kulut tuloihin, osoittautuivat Suomen suuret mansikkatilat kilpailuetuisimmiksi. Tähän tulokseen on kuitenkin syytä suhtautua varauksella, sillä suurten mansikkatilojen tulojen määrä, etenkin tukien osalta, saattaa olla todellisuudessa laskelmassa käytettyä tulomäärä pienempi. Tämä sen vuoksi, että mansikantuotannon tuet oli määritelty kohdistamalla koko tilan puutarhatalouden tuet mansikanviljelypinta-alan suhteessa, jolloin tilan tukienhaku aktiivisuus ja muiden puutarhakasvien tuet vaikuttavat mansikantuotannon tukien määrään. Suomen suurten mansikkatilojen jälkeen seuraavaksi kilpailuetuisimpia olivat Viron suuret mansikkatilat. Suomen keskisuuret ja pienet mansikkatilat osoittautuivat kilpailuedultaan hyvin heikoiksi, sillä niillä mansikantuotannon kulut ylittivät mansikantuotannon tulot.

Yritystason kustannusedussa on huomioitava myös kustannusedun pysyvyys. Viron merkittävin kustannusedun lähde, alhaiset palkkatyön kustannukset, eivät ole todennäköisesti pitkäaikaisia. Viron tilastokeskuksen (Statistical office of Estonia 2004) mukaan maataloustyöntekijöiden keskipalkka on noussut 67 \% vuodesta 1998 vuoteen 2003. Keskimäärin Viron palkat ovat nousseet vuodessa lähes $10 \%$ (STT 2004). Mikäli palkkakustannukset nousevat Virossa aikaisemman kehityksen mukaisesti, on Viron alhaisten palkkakustannusten tuoma kilpailuetu menetetty runsaan kymmenen vuoden päästä.

Merkittävin ero Suomen ja Viron mansikantuotannon toimialoissa olivat erilaiset ostajat. Suomalaiselle mansikanostajalle oli tyypillistä, että kyseessä oli tuoremansikkaa ostava kuluttaja, jolla oli vahva kotimaisuuspreferenssi (Kaunisto 2001, Tillgrén \& Kupiainen 2002). Suomessa mansikan kysyntä on melko vakaata, eivätkä ostomäärät ole viime vuosina merkittävästi muuttuneet. Viron mansikanostajat olivat Suomen mansikanostajia heterogeenisempi joukko. Virossa merkittäviä mansikanostajia olivat sekä kuluttajat että teollisuus. Viron mansikan ostot tulevat kasvamaan tulevaisuudessa, sillä kotitarveviljelyn määrä vähentyy jatkuvasti ja ihmisten ostovoima kasvaa elintason nousun myötä. Teollisuuden ostot tulevat Virossa kuitenkin vähenemään, sillä teollisuus korvaa enenevässä määrin virolaista mansikkaa tuontimansikalla.

Toimialatason ja maatason kilpailuedusta Suomen ja Viron välillä voidaan tehdä subjektiivinen arvio. Arvio perustuu käsitykseen siitä, mikä on eduksi ja haitaksi kilpailuedun kannalta. Tämän arvion perusteella Suomella on toimialatasolla kilpailuetu Viroon nähden, ja maatasolla Virolla on kilpailuetu Suomeen nähden. Toimialatason kilpailuedun lähteinä Suomessa toimivat pääasiassa kehittyneemmän yhteiskunnan ja korkeamman elintasot tuomat edut, kuten järjestäytyneet viljelijät ja valveutuneet ostajat. Maatason kilpailuedun lähteinä Virossa toimivat paremmat perustuotannontekijät, jotka ovat maataloussidonnaisessa tuotannossa hyvin merkittävässä asemassa. 


\section{Kirjallisuus}

FAO 2004. Faostat. Viitattu 14.9.2004. Saatavilla: http://faostat.fao.org/faostat/.

Frohberg \& Hartmann ed. 1998. Competitiveness of the Baltic Agricultural and Food Sectors after Accession to the EU. Phare ACE Research Project, Final Report, mimeo.

Hajdu, I. \& Lakner, Z. 1998. Effect of Economic Policy on Competitiveness of Hungarian Food Industry. A Kerstészeti és Élelmiszeripari Egyetem Közleményei. Vol. LVII. Publicationes Universitatis Horticulturae. Budapest: Universitas horticulturae industriaeque alimentariae.

Kleijn, E. H. J. M. 1995. Application of the Porter methodology in analyzing the competitive advantage of horticultural branches. Acta-Horticulturae, Number 340. Wageningen: International Society for Horticulture Science: 53-58.

Laitinen, E. 1995. EU:n puutarhamarkkinat, nykytila ja uudistusehdotukset. Maa- ja metsätaloustuottajain keskusliiton julkaisuja n:o 134. Helsinki: Maa- ja metsätaloustuottajain keskusliitto MTK.

Lehtimäki, S. 1998. Suomen puutarhatuotannon EU-sopeutumisen jatkoseuranta ja EU:n puutarhareformi. Puutarhaliiton julkaisuja nro. 300. Helsinki: Puutarhaliitto.

Libek, A. 2002. Evaluation of Strawberry Cultivars in Estonia. Acta Horticulturae, Number 567. Leuven: International Society for Horticultural Science: 207-210.

MMM 2004. Puutarhayritysrekisteri 2003. Helsinki: Maa- ja metsätalousministeriön tietopalvelukeskus

Mäkelä, S., Norri, O. \& Mehl, K. 1995. Vihannesten alkutuotannon ja jalostuksen menestystekijät. Tuotantoja kustannusvertailu eräissä Euroopan maissa. Pyhäjärvi-instituutin julkaisuja 15. Eura: Pyhäjärvi-instituutti.

Traill, W.-B. \& Pitts, E. 1997. Uncompetitiveness in a Primary Product: does Porter help? The case of UK horticulture (abstract). Competitiveness-in-the-food-industry. London: Blackie Academic \& Professional: 118148.

Porter, M. E. 1985. Competitive Advantage, Creating and Sustaining Superior Performance. New York: Free Press.

Porter, M. E. 1987. Strategia kilpailutilanteessa: toimialojen ja kilpailijoiden analysointitekniikat. Helsinki: Rastor.

Porter, M. E. 1990. The Comparative Advantage of Nations. London: Macmillan.

Statistical Office of Estonia 2004. Põllumajandus, Agriculture 2003. Aastakogumik Yearbook. Tallinn.

Värnik, R. 2001. Maasikakasvatuse efektiivsus Eestis. Dissertationes Rerem Oeconomicarum Universitatis Agriculturea Estoniae. Tartu: Tartu Ûlikooli Kirjastuse trükikoda. 